HaYes, W. (1953). J. gen. Microbiol. 8, 72-88.

\title{
Observations on a Transmissible Agent Determining Sexual Differentiation in Bacterium coli
}

\author{
BY W. HAYES \\ Department of Bacteriology, Postgraduate Medical School of London, \\ Ducane Road, London W. 12
}

\begin{abstract}
SUMMARY: Analysis of a pair of Bacterium coli K-12 mutants which had ceased to show genetic recombination after storage, implicated mutant 58-161, which had previously behaved as a gene donor strain, as the infertile parent. Infertile 58-161 failed to display recombination when crossed with a gene acceptor strain (W-677) but was able to mate successfully with wild-type K-12 and prototrophic recombinant donor strains, i.e. it had become a gene acceptor. The terms ' $F+$ ' and ' $F_{-}$' ' have been adopted (after Lederberg, Cavalli \& Lederberg, 1952) to denote donor and acceptor strains respectively. Growth of either 58-161/F - or $\mathrm{W}-677 / \mathrm{F}$ - in mixed broth culture with 58-161/F + resulted in the conversion to $\mathbf{F}+$ of up to $75 \%$ of re-isolated colonies of the initially F - strain. F - strains converted to $\mathrm{F}+$ by strains of dissimilar genotype showed no phenotypic alteration and, therefore, were not recombinants. Washed, mixed cultures on minimal agar yielded an $\mathrm{F}+$ conversion rate of only $3.6 \%$, while $100 \%$ recombinants were $\mathrm{F}+$ under the same conditions. The $\mathbf{F}+$ agent could be transmitted serially through F - strains and was not filterable. While $F-\times F-$ crosses were sterile, $F+\times F-$ crosses showed maximum fertility. $\mathrm{F}+\times \mathrm{F}+$ crosses were $c .10-20$ times less productive than $\mathbf{F}+\times \mathbf{F}-$. The $\mathbf{F}+$ agent had a determining effect on the phenotype of recombinants. Thus, when the $\mathbf{F}+\mathbf{F}-$ relationship was reversed in $\mathbf{F}+\times \mathbf{F}-$ crosses between the same pair of mutants, almost all recombinants which did not show new patterns of unselected marker characters had the phenotype of the $\mathbf{F}-$ parent. Among recombinants from $\mathrm{F}+\times \mathrm{F}+$ crosses, the phenotypes of both parents were represented though not always equally. This effect of $F+$ on the phenotype of segregants invalidates much of the evidence for genetic linkage in K-12. Reversal of $\mathbf{F}+$ potential in otherwise similar crosses also had a marked effect on the efficiency of prototroph formation on minimal agar supplemented with various growth factors required by one of the parent auxotrophs. A tentative theory of the mechanism of recombination is presented on the basis of this and previous work. This supposes that $\mathbf{F}+$ is a non-lytic infectious agent, harboured by $\mathbf{F}+$ cells and absent from $\mathbf{F}-$ cells, which becomes effectively associated with a part (or parts) of the chromosomes of a small proportion of the cells it inhabits. The $\mathbf{F}+$ agent thus acts as a gene carrier in the transfer of genetic material from $\mathrm{F}+$ to $\mathrm{F}-$ cells.
\end{abstract}

Genetic recombination in bacteria was first demonstrated in the K-12 strain of Bacterium coli (Lederberg \& Tatum, 1946; Tatum \& Lederberg, 1947) and its occurrence in this strain has since been confirmed by many workers. Lederberg, Cavalli \& Lederberg (1952) have recently reported some forty strains of Bact. coli from over 2000 separate isolates which either out-cross with K-12 mutants or show inter-fertility, so that genetic recombination may be considered a not uncommon feature of this species when such potential incompatibility factors as colicine production and lysogenicity are taken into account (Lederberg, 1951).

When irradiation-induced mutants of K-12, having two or more comple- 
mentary nutritional dependencies, were grown together in a complete medium and the mixed culture washed free of nutrients and plated in minimal agar, one colony developed for every $10^{6}-10^{7}$ cells seeded (Lederberg \& Tatum, 1946). The cells of these colonies were prototrophic, i.e. they resembled the wild-type strain in having acquired the inheritable capacity to synthesize all the growth factors upon which the mutant strains were dependent. The mutant strains did not show mutational reversion to prototrophism when cultured separately in minimal agar. By a further series of mutational steps the auxotrophic 'parent' mutants were labelled with a number of complementary differences in characters, such as fermentative capacity and phage resistance or sensitivity, which were not selected by growth in minimal medium. Analysis revealed that the patterns of these unselected marker characters in prototrophs frequently differed from that in either mutant, while their distribution afforded plausible evidence of linkage (Lederberg, 1947). Since culture filtrates of either mutant were incompetent in recombination (Davis, 1950) it seemed reasonable to assume as a working hypothesis that the genetic rearrangements found in prototroph clones were the outcome of a more or less orthodox sexual mechanism involving zygote formation, crossing over and meiosis. The validity of this assumption was strengthened when Lederberg (1949; Zelle \& Lederberg, 1951) described the occurrence of prototroph strains which behaved like heterozygous diploids in continually segregating out different but stable recombination types. As a result of these findings, most published work on recombination in K-12 has been concerned with the elaboration of linkage behaviour and the application of the phenomenon to analysis of such problems as the genetic basis of resistance to antibiotics (e.g. Cavalli \& Maccacaro, 1950; Newcombe \& Nyholm, 1950a, $b$ ), while further investigation of the mechanism of recombination itself has been somewhat neglected.

The first indication of sexual differentiation among K-12 mutants was the observation by Hayes (1952 $a$ ) that streptomycin destroyed the fertility of only one of the two equally sensitive mutants with which he worked. He interpreted this differential action of streptomycin as providing evidence against the occurrence of conjugation and as suggesting the uni-directional transfer of genetic material from a 'gene donor' to a 'gene acceptor' cell. $\mathrm{He}$ postulated that the living donor cell extruded genetic elements which adhered to its surface so that the cell could continue to function as a gene carrier despite its subsequent 'killing' by streptomycin. On the other hand, the role of the acceptor cell was the vital one of taking up genes from the donor cell and incorporating them into its genetic structure. Hayes $(1952 b)$ later showed that exposure of his donor strain to small doses of ultraviolet light increased its fertility fivefold or more, while similar treatment of the acceptor strain reduced fertility pari passu with the viable count. Moreover, the conditions necessary for ultraviolet enhancement of donor cell fertility closely paralleled those described by Lwoff and others (Lwoff, Siminovitch \& Kjelgaard, $1950 a, b$; Lwoff, 1951) for the maturation of prophage and subsequent liberation of lytic phage from lysogenic bacteria. Since both K-12 mutants carried 
$\lambda$ phage (Weigle $\&$ Delbrück, 1951), which has been excluded as a possible agent of recombination (Lederberg, personal correspondence; Lederberg et al. 1952), it was undecided whether the effect of ultraviolet irradiation on donor cell fertility was primary or merely secondary to $\lambda$ release, as suggested to the author by Lederberg.

Confirmation of sexual differentiation between $\mathrm{K}-12$ mutants has been reported by Lederberg et al. (1952), whose findings are essentially similar to those described below. This paper concerns an investigation into the cause of infertility arising spontaneously in a pair of K-12 mutants which had previously shown normal recombination.

\section{MATERIALS AND METHODS}

Bacterial strains

(a) K-12 (wild-type strain). This strain is prototrophic and grows well in unsupplemented minimal medium.

(b) 58-161. A methionine-requiring ( $\mathrm{M}-)$ mutant of K-12 which ferments lactose, maltose, mannitol, galactose, xylose and arabinose, is sensitive to coliphage $\mathrm{T}_{1}$ and resistant to $\mathrm{T}_{3} \quad(\mathrm{Lac}+\mathrm{Mal}+\mathrm{Mann}+\mathrm{Gal}+\mathrm{Xyl}+\mathrm{Arab}+$ $\mathrm{T}_{1} \mathrm{~s} \mathrm{~T}_{3} \mathrm{r}$ ). This mutant was originally described as biotin-dependent as well as M - (Lederberg, 1947). Since, however, it grows optimally in minimal medium + methionine alone, and in which glucose is substituted by an acid hydrolysate of pure sucrose (kindly supplied by Thomas Kerfoot and Co., Vale of Bardsley, Lancashire) it must be presumed not to require biotin now. Despite this, its rate of back-mutation to prototrophism is, fortunately, extremely low, and the development of $\mathrm{M}+$ colonies has never been observed from control platings on minimal agar under the conditions employed in recombination tests.

(c) W-677. A mutant of $\mathbf{K}-12$ requiring threonine, leucine and thiamine (vitamin $\left.\mathrm{B}_{1}\right)\left(\mathrm{TLB}_{1}-\right)$. Its marker characters are complementary to those of 58-161 (i.e. Lac - Mal - Mann - Gal - Xyl - Arab - $\mathrm{T}_{1}{ }^{\mathrm{r}} \mathrm{T}_{3}{ }^{\mathrm{s}}$ ).

(d) Streptomycin (SM)-resistant mutants (58-161/Sr, W-677/Sr etc.) were selected by plating very large inocula of each strain on nutrient agar containing 200-250 $\mu \mathrm{g}$. SM/ml. The largest and most rapidly growing colonies were picked, purified by replating on SM-agar and tested for growth on agar without SM. Only one $\mathbf{S}^{\mathbf{r}}$ mutant of each strain was used throughout this work. The nutritional and marker characters of these $S^{r}$ mutants were identical with those of their parent strains.

Stock cultures were maintained on Dorset's egg medium at $4^{\circ}$ whence subcultures were made to nutrient broth as required.

Media. The constitution of minimal agar (MA) was that recommended by Tatum \& Lederberg (1947) except that asparagine was omitted. Except when otherwise stated, this medium was supplemented with thiamine $\left(\mathbf{M A}+\mathbf{B}_{1}\right)$ in a final concentration of $0.0005 \%(w / v)$. The term 'prototroph' should properly be reserved for those recombinants having the nutritional independence of the wild-type. Although the majority of recombinants arising on $\mathbf{M A}+\mathrm{B}_{1}$ are 
$\mathbf{B}_{1}-$, the word 'prototroph' will, for convenience, still be applied to all colonies developing on this medium.

Nutrient broth and nutrient agar were those routinely employed by this department and were prepared from a tryptic digest of beef. Whenever possible, the same batch of medium was used over long periods and always throughout one experiment.

\section{Technique of recombination tests}

(1) Standard technique. Bottles of nutrient broth at $37^{\circ}$ were seeded separately with $1 / 10$ vol. overnight broth culture of each of the two strains to be mated. After $3-5 \mathrm{hr}$. growth at $37^{\circ}, 5 \mathrm{ml}$. of each culture were mixed, centrifuged at once, and the deposit washed in three changes of $0.9 \%(\mathrm{w} / \mathrm{v})$ $\mathrm{NaCl}$ buffered at $\mathrm{pH} \mathbf{7 \cdot 2}$ (hereafter referred to as saline) and resuspended in $\mathbf{1 . 0} \mathrm{ml}$. saline. A standard loopful (i.e. a fully charged $2 \mathrm{~mm}$. diameter welded platinum loop $=c .0 .01 \mathrm{ml}$.) of this suspension was transferred to the surface of $\mathbf{M A}+\mathrm{B}_{1}$ in $3 \mathrm{~cm}$. diameter plates and uniformly distributed with a small glass spreader. Tests involving counts of prototroph colonies were always duplicated or triplicated and the counts made after $40-45 \mathrm{hr}$. at $37^{\circ}$. Using this technique, the usual 58-161 $\times$ W-677 mating yielded 20-80 prototroph colonies per plate, depending on the age of the broth cultures employed. With less efficient mating systems the mixture, after washing, was resuspended in appropriate smaller volumes of saline.

(2) Simplified screening technique. Later in this work the need arose for a technique whereby large numbers of colonies could be tested rapidly for capacity to show recombination with a gene acceptor (indicator) strain. A portion of each colony to be tested was picked with a platinum loop and rubbed over an area $c .0 .75 \mathrm{~cm}$. diameter on the surface of a nutrient agar plate. About thirty such areas could be accommodated on a $9 \mathrm{~cm}$. diameter plate. After 1-1.5 hr. at $37^{\circ}$ the plate was exposed to a standard dose of ultraviolet light and reincubated for $1 \mathrm{hr}$. The growth on each area was then thoroughly rubbed up in a standard $(2 \mathrm{~mm}$.) loopful of a young broth culture of the indicator strain and the plate reincubated at $37^{\circ}$ overnight. The mixed growth from each area was suspended in $\mathbf{0 . 5} \mathrm{ml}$. saline and a standard loopful of this suspension spread over an area of similar size on $\mathbf{M A}+\mathbf{B}_{\mathbf{1}}$. Recombination was assessed by the presence or absence of colonies after c. $42 \mathrm{hr}$. at $37^{\circ}$. The small amount of nutrient material in the dense saline suspensions usually initiated considerable confluent syntrophic growth but this did not seriously interfere with the reading of results. When the colonies to be tested were $S^{8}$, an $S^{r}$ indicator strain was employed and $S M$ incorporated in the $M A+B_{1}$. This effectively abolished syntrophic growth without affecting the development of prototroph colonies. Falsely positive results do not arise with this screening technique, while false negatives never exceeded $10 \%$ and were usually considerably lower. Cultures of all colonies showing aberrant or unexpected results were checked by the standard technique after exposure to ultraviolet irradiation.

Total viable counts. A $1 / 10^{5}$ (or other appropriate) dilution of each broth 
culture was made just before mixing, and standard ( $2 \mathrm{~mm}$.) loopfuls spread on nutrient agar in triplicate. Colonies were counted after $16-18 \mathrm{hr}$. at $30^{\circ}$. Since the strains of bacteria used were 'rough' (with one exception mentioned below), loss of cells during washing was negligible, so that results of viable counts indicated fairly accurately the actual numbers of cells of each mutant participating in recombination.

\section{Technique for determining marker characters of prototrophs}

The surfaces of prototroph colonies on $\mathbf{M A}+\mathbf{B}_{\mathbf{1}}$ were touched with a sterile wire which was then rubbed over nutrient agar slants in such a way as to yield isolated colonies. After incubation a well separated colony of each isolate was picked and suspended in a small volume of saline to yield a faint turbidity. Using a straight wire, a very small inoculum from these suspensions was spotted to points on the surface of a series of solid indicator media in $9 \mathrm{~cm}$. diameter plates positioned over a template. The following media were used:

(1) Fermentative capacity. Peptone water-agar containing $1 \cdot 0 \%(\mathrm{w} / \mathrm{v})$ of the carbohydrate + neutral red as indicator.

(2) Phage resistance or sensitivity. Nutrient agar plates flooded with undiluted phage suspension containing not less than $10^{9}$ particles $/ \mathrm{ml}$., the excess fluid being withdrawn and the plates dried.

(3) Streptomycin sensitivity or resistance. Nutrient agar containing 200-250 $\mu \mathrm{g} . / \mathrm{ml}$. streptomycin (SM). A plate of $\mathbf{M A}+\mathbf{B}_{1}$ was always included in the series as a check on prototrophism.

In some later experiments involving the testing of considerable numbers of prototrophs for fermentative and SM characters only, prototroph colonies were touched with a sterile wire and spotted directly to a series of plates of $\mathrm{MA}+\mathrm{B}_{1}$ containing the test carbohydrates in place of glucose (growth indicating fermentation), and of $\mathrm{MA}+\mathrm{B}_{1}+$ glucose $+\mathrm{SM}(200 \mu \mathrm{g} . / \mathrm{ml}$.).

\section{RESULTS}

A strain of each of the K-12 mutants 58-161 and W-677 which had ceased to yield prototroph colonies in mixed culture after storage for a year on inspissated egg in the refrigerator, were kindly supplied by Dr C. C. Spicer. These strains, which will be referred to initially as 58-161/sp and W-677/sp, were shown to be identical in their nutritional and marker characters to the fertile strains of the same designation described above.

\section{Analysis of the infertile 58-161/sp $\times W-677 / \mathrm{sp}$ mating}

Each strain was crossed with the heterologous fertile mutant. The mating 58-161 $\times \mathrm{W}-677 / s p$ yielded about the same number of prototrophs as $58-161 \times \mathrm{W}-677$, while the 58-161/sp $\times \mathrm{W}-677$ and $58-161 / s p \times \mathrm{W}-677 / s p$ matings were sterile. The inference that 58-161/sp was the defective partner of the infertile combination was confirmed for fifteen colonies from a plating of this strain. In order to demonstrate, in so far as was possible, that the infertility of 58-161/sp was complete and not merely minimal, a culture of one 
of these colonies was tested for recombination with $W-677$ after ultraviolet irradiation under optimal conditions. No recombination was observed. Following irradiation, however, strain 58-161/sp (like 58-161 and W-677) liberated $\lambda$ phage so that its infertility was not due to failure of some genetic mechanism potentiated by the lysis accompanying phage release.

\section{Behaviour of infertile 58-161/sp as a gene acceptor}

These findings had been predicted by the hypothesis that gene donor cells (58-161) differed from gene acceptor cells (W-677) only in the possession of an agency whereby genes, or groups of genes, could be transferred outside the cell and thence, by contact, to an acceptor cell. For the sake of simple exposition the term 'carrier' will be used to denote this agency without any implications as to its nature or function. It seemed, therefore, that the most likely cause of infertility in a previously fertile combination was loss by the donor partner of its carrier. The cells of such a strain would be similar to acceptor cells so far as their potential for recombination was concerned, and should therefore be capable of mating and forming prototrophs with a donor strain of dissimilar genotype.

A streptomycin-resistant mutant of $58-161 / s p$ was selected $\left(58-161 / s p / \mathrm{S}^{\mathrm{r}}\right)$ and tested in comparison with $\mathrm{W}-677 / \mathrm{S}^{\mathrm{r}}$ for ability to show recombination with K-12 (wild-type) and with ten prototroph strains derived from a 58-161 $\times$ W-677 cross. The 'SRP' (streptomycin-resistant prototroph) method described by Lederberg (1951) was used, in which a mixture of an $\mathrm{Sr}^{\mathrm{r}}$ mutant of a nutritionally dependent strain (e.g. $W-677 / S^{r}$ ) and an $S^{8}$ prototrophic strain is seeded to MA + SM which prevents growth of both parent strains but allows $\mathrm{S}^{\mathrm{r}}$ prototrophic recombinants to develop into colonies. Since the rate of mutation to $\mathrm{Sr}^{\mathrm{r}}$ is about one $/ 10^{\mathbf{1 0}}$ cell generations in Bact. coli (Newcombe \& Hawirko, 1949) the ratio of mutant to recombinant colonies is insignificant. In the present series of tests, control platings of double inocula of each strain on $\mathrm{MA}+\mathrm{B}_{1}+\mathrm{SM}$ yielded no mutant colonies. Strain $58-161 / \mathrm{sp} / \mathrm{Sr}^{\mathrm{r}}$ proved fertile when mated with K-12 and yielded about the same number of recombinant colonies as the $\mathrm{K}-12 \times \mathrm{W}-677 / \mathrm{Sr}^{\mathrm{r}}$ cross. Similarly, 58-161 $/ s p / \mathrm{S}^{\mathrm{r}}$ was successfully mated with nine of the ten prototroph recombinant strains tested, the one strain which did not form recombinants failing to do so with $\mathrm{W}-677 / \mathrm{S}^{\mathrm{r}}$ also. The findings described above are summarized in Table 1. It was evident from this analysis that 58-161/sp had lost its donor properties and had in consequence become an acceptor strain displaying the same degree of fertility as W-677 in matings with K-12 and other prototroph donors.

Lederberg et al. (1952), in an independent and closely parallel investigation, have suggested the symbol ' $\mathrm{F}-$ ' to denote strains which are completely infertile on mating together, and ' $\mathrm{F}+$ ' to denote strains which form fertile matings with $\mathbf{F}$ - as well as with other $\mathbf{F}+$ strains. Since it has become quite clear that the term 'donor' is synonymous with ' $\mathbf{F +}$ ' and 'acceptor' with ' $F$-', this convenient terminology will be used henceforth in this paper. Thus 58-161 is $\mathrm{F}+$, and $\mathrm{W}-677$ and $58-161 / s p$ are $\mathrm{F}-$. 


\section{Restoration of 58-161/F - fertility}

Working on the assumption that the alteration of 58-161/sp from $\mathrm{F}+$ to F - was due to loss of a gene carrier, it seemed possible that this strain might be able to reacquire its carrier by infection from an $\mathbf{F}+$ strain of similar genotype, and thus be restored to the $\mathbf{F}+$ state, in much the same way that lysogenic bacteria which have lost their phage can reacquire it by infection.

Table 1. Summary of results of various matings relating to fertility analysis of the sterile pair of $K-12$ mutants 58-161/sp and $W-677 / \mathrm{sp}$

\begin{tabular}{|c|c|c|}
\hline Object of matings & Matings & $\begin{array}{c}\text { (Average of } \\
\text { duplicates) }\end{array}$ \\
\hline Initial analysis & $\begin{array}{l}58-161 / s p \times W-677 / s p \\
58-161 / s p \times W-677 \\
58-161 \times W-677 / s p \\
58-161 \times W-677\end{array}$ & $\begin{array}{r}0 \\
0 \\
109 \\
71\end{array}$ \\
\hline $\begin{array}{l}\text { Confirmation by sensitive ultra- } \\
\text { violet technique }\end{array}$ & $\begin{array}{l}58-161 / s p / U V \times W-677 \\
58-161 \times W-677 \\
58-161 / U V \times W-677\end{array}$ & $\begin{array}{r}0 \\
52 \\
365\end{array}$ \\
\hline $\begin{array}{l}\text { Behaviour of infertile 'donor' strain } \\
\text { as a gene acceptor }\end{array}$ & 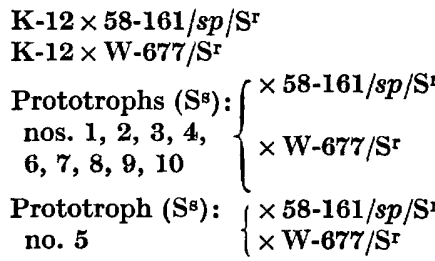 & $\begin{array}{l}144 \\
180 \\
\text { Numerous, } \\
\text { not counted } \\
\text { Numerous, } \\
\text { not counted } \\
0 \\
0\end{array}$ \\
\hline
\end{tabular}

58-161 and $W-677=$ mutants of fertile combination.

58-161/sp and $W-677 / s p=$ mutants of sterile combination obtained from Dr C. C. Spicer. $/ \mathrm{UV}=$ exposed to standard dosage ultraviolet light, followed by incubation in nutrient broth for $60 \mathrm{~min}$. prior to mixing with $\mathrm{W}-67 \mathrm{r} 7$ culture and washing.

$/ \mathrm{S}^{r}=$ streptomycin-resistant mutant.

$\mathrm{S}^{\mathrm{s}}$ prototrophs derived from a 58-161 $\times \mathrm{W}-677$ mating.

Strain $58-161 / \mathrm{S}^{\mathrm{r}} / \mathrm{F}$ - was marked by resistance to $0.002 \mathrm{M}$-sodium azide $\left(A z^{r}\right)$ so that it could be selected from mixed culture with a doubly sensitive strain and identified with certainty. To a young broth culture of 58-161/F+, $1 / 20$ vol. of a similar culture of $58-161 / \mathrm{Sr}^{\mathrm{r}} \mathrm{Az} / \mathrm{F}$ - was added and the mixture incubated overnight at $37^{\circ}$. A loopful was plated on nutrient agar +SM. After incubation, twenty-five well isolated colonies were picked, purified by replating on SM-agar and checked for azide resistance. Each of the twenty-five recovered strains was then tested by the screening technique for recombination with $\mathrm{W}-677 / \mathrm{F}-$. In two separate experiments, $8 / 25$ and $10 / 25$ recovered strains (i.e. an average of $36 \%$ ) yielded prototroph colonies and had, therefore, become $\mathbf{F}+$.

$$
F+\text { transfer between strains of dissimilar genotype }
$$

The uniquely high rate of $\mathrm{F}-$ to $\mathrm{F}+$ transformation in 58-161/F - suggested that 58-161/F + might transfer its $\mathrm{F}+$ factor to $\mathrm{W}-677 / \mathrm{F}$ - with equal efficiency. An $\mathrm{S}^{\mathrm{r}} \mathrm{Az}{ }^{\mathrm{r}}$ mutant of $\mathrm{W}-677 / \mathrm{F}$ - was grown in mixed culture 
with 58-161/F + under the same conditions as in the previous experiments. Recovered $\mathrm{W}-677 / \mathrm{S}^{\mathrm{r}} \mathrm{Az} \mathrm{r}^{\mathrm{r}}$ isolates showed a $75 \%$ conversion rate to $\mathbf{F}+$ as shown by the ability of the isolates to yield prototrophs with 58-161/F - . Repeated experiments using the same technique, or simply employing fermentation capacity as a marker when the originally $\mathbf{F}-$ strain was $\mathbf{S}^{\mathbf{s}} \mathbf{A} z^{\mathbf{s}}$, have never shown a conversion rate of less than $40 \%$ after overnight mixed culture in nutrient broth.

It was realized that the concept upon which these experiments had been planned, i.e. that the agent responsible for $\mathrm{F}+$ transfer and the carrier concerned in recombination were the same, now seemed to lead to the paradox that the real recombination rate was about a million times greater than the rate demonstrable by the usual technique of prototroph selection. If this was indeed the case, frequent rearrangements of marker and nutritional characters would be expected among $\mathrm{F}+$ isolates from an $\mathrm{F}$ - strain converted by an $\mathbf{F}+$ strain of complementary genotype. Twenty-five $\mathbf{W}-677 / \mathbf{F}+$ isolates, from two separate mixed cultures of $\mathrm{W}-677 / \mathrm{F}$ - and $58-161 / \mathrm{F}+$, were tested for alteration in each of ten characters which distinguish W-677 from 58-161. All the isolates conformed to W-677 phenotype.

\section{Properties of the $F+$ agent}

For technical reasons only a small number of experiments on the character of the $\mathbf{F}+$ agent have as yet been performed. The results of certain of these experiments are sufficiently clear-cut, however, to warrant reporting.

Transmissibility and stability. The $\mathbf{F}+$ agent appears to be indefinitely transmissible through a series of $\mathrm{F}$ - strains. For example, in the course of preparing various $\mathbf{F}+$ stocks, the following series of transfers was effected without apparent loss in efficiency of transmission:

$$
58-161 / \mathrm{F}+\rightarrow \mathrm{W}-677 / \mathrm{Sr}^{\mathrm{r} A z^{\mathrm{r}}} / \mathrm{F}-\rightarrow 58-161 / \mathrm{F}-\rightarrow \mathrm{W}-677 / \mathrm{F}-\underset{58-161 / \mathrm{S}^{\mathrm{r}} \mathrm{Az}}{\mathrm{r}} / \mathrm{F}-.
$$

Stocks of F + strains obtained in this way have proved stable on subculture and on storage for several months on Dorset's egg medium at $4^{\circ}$.

Filterability. The $\mathbf{F}+$ agent appears to be held back by a collodion membrane of $0 \cdot 74 \mu$. A.P.D. In three experiments, overnight growth of W-677/F in filtrates of young broth cultures of $58-161 / F+$ failed to yield any recombinants or any $\mathrm{F}+$ isolates from a total of 115 colonies tested. Even if only a very small number of $\mathbf{F}+$ agents had passed the filter, a disproportionately large number of conversions would be expected from autoinfection during overnight incubation.

$F+$ transfer in relation to prototroph development on $M A$. Since all except one of a considerable number of recombinant prototrophs from $\mathrm{F}+\times \mathrm{F}-$ crosses had proved to be $\mathbf{F}+$, it was decided to determine whether the high efficiency of $\mathbf{F}-$ to $\mathbf{F}+$ conversion in nutrient broth obtained also under actual conditions of recombination on $\mathbf{M A}+\mathbf{B}_{\mathbf{1}}$. A washed suspension of a mixture of $58-161 / \mathrm{F}+$ and $\mathrm{W}-677 / \mathrm{F}$ - was prepared under standard conditions and three drops $\left(c .0 .06 \mathrm{ml}\right.$.) spread evenly over the surface of $\mathbf{M A}+\mathbf{B}_{1}$ 
in a $9 \mathrm{~cm}$. diameter plate. After $24 \mathrm{hr}$. at $37^{\circ}$ developing prototroph colonies were clearly discernible with a hand-lens. Sweeps were made with a wire loop from four areas on the plate (taking care to avoid prototroph colonies), the organisms suspended in saline and then plated on lactose indicator medium. After incubation, $60 \mathrm{~W}-677$ (non-lactose-fermenting) colonies were picked and tested for recombination with 58-161/F - Only $2 / 60$ isolates had become $\mathbf{F}+$. On the other hand, when sixty of 102 prototroph colonies which had arisen on the original plate were picked, purified and tested for recombination with $58-161 / \mathrm{F}$ - by precisely the same technique as before, $55 / 60$ were found to be $\mathrm{F}+$. The remaining five strains which appeared $\mathrm{F}-$ proved to be $\mathrm{F}+$ also when re-tested by the standard technique following ultraviolet irradiation. Thus, when tested under similar conditions, the $\mathbf{F}+$ conversion rate of nonrecombinant $\mathrm{F}$ - cells under the actual conditions of the recombination test was only $3.6 \%$, while that of recombinants was $100 \%$.

\section{The relative efficiency of $\boldsymbol{F}+\times \boldsymbol{F}-$ and $\boldsymbol{F}+\times \boldsymbol{F}+$ crosses}

The obvious relevance of the $\mathrm{F}+$ agent to the recombination process, as shown by the sterility of $\mathbf{F}-\times \mathbf{F}-$ matings, implied that fertility depended either on both mating cells being $\mathbf{F}+$, or on one being $\mathbf{F}+$ and the other $\mathbf{F}-$. If possession of $\mathbf{F}+$ by each of two cells is necessary for mating, then clearly an $\mathbf{F}+\times \mathbf{F}+$ cross should be more efficient than an $\mathbf{F}+\times \mathbf{F}-$ one since in the former all the cells are compatible from the start, while in the latter, mating must occur in two stages-first the transference of $\mathbf{F}+$ to the $\mathbf{F}$ partner (which was shown above to be inefficient under recombination conditions on MA) and, secondly, the actual mating between the now compatible $\mathbf{F}+$ cells. On the other hand, if an $\mathrm{F}+$ cell is merely one which possesses a carrier (i.e. is a gene donor) which can only be taken up by a carrier-free $\mathbf{F}$ - cell, then an $\mathbf{F}+\times \mathbf{F}$ - cross should be much the more productive. The details of one of several such comparative experiments are given in Table 2.

\section{Table 2. Relative efficiency of $F+\times F-$ and $F+\times F+$ matings}

Standard recombination technique employed

\begin{tabular}{|c|c|c|c|c|c|c|c|}
\hline \multirow{4}{*}{$\begin{array}{c}\text { Matings } \\
58-161 / \mathrm{F}+\times W-677 / \mathrm{F}-\end{array}$} & \multirow{2}{*}{\multicolumn{4}{|c|}{ No. prototroph colonies }} & \multirow{4}{*}{$\begin{array}{l}\text { Av. } \\
97\end{array}$} & \multicolumn{2}{|c|}{$\begin{array}{l}\text { Total viable counts } \\
\text { (av. of triplicates) }\end{array}$} \\
\hline & & & & & & & Organisms \\
\hline & 8 & & & & & Strain & per ml. \\
\hline & 92 & 105 & 108 & 82 & & $\begin{array}{l}58-161 / F+ \\
58-161 / F-\end{array}$ & $\begin{array}{l}945 \times 10^{6} \\
828 \times 10^{8}\end{array}$ \\
\hline $58-161 / F+\times W-677 / F+$ & 5 & $\mathbf{2}$ & 4 & 5 & 4 & $\mathrm{~W}-677 / \mathrm{F}+$ & $477 \times 10^{6}$ \\
\hline $58-161 / F-\times W-677 / F+$ & 39 & 59 & nt & nt & 49 & $\mathrm{~W}-677 / \mathrm{F}-$ & $450 \times 10^{6}$ \\
\hline
\end{tabular}

Strain 58-161/F+ = original F + strain; strain 58-161/F $-=58-161 / s p$.; strain $\mathrm{W}-677 / \mathrm{F}+$ $=\mathrm{W}-677 / \mathrm{F}-$ converted to $\mathrm{F}+$ by $58-161 / \mathrm{F}+$.

$\mathrm{nt}=$ no test performed.

It will be seen that the $58-161 / \mathrm{F}+\times \mathrm{W}-677 / \mathrm{F}-$ cross yielded $c .20$ times as many prototrophs as $58-161 / \mathrm{F}+\times \mathrm{W}-677 / \mathrm{F}+$. That this result was not due to some abnormality of $\mathbf{W}-677 / \mathbf{F}+$, apart from its acquisition of $F+$, is shown 
by the 12 -fold rise in recombination rate when this strain was crossed with 58-161/F - Strain 112-12, a non-lysogenic cystine- and histidine-requiring F + mutant of K-12 (kindly supplied by Dr A. Lwoff and Dr E. Wollman), was similarly tested against $\mathrm{F}+$ and $\mathrm{F}-$ strains of 58-161 and $\mathrm{W}-677$. In each case the $\mathbf{F}+\times \mathbf{F}-$ cross was 15-30 times more productive than $\mathbf{F}+\times \mathbf{F}+$.

Strain $58-161 / \mathrm{F}$ - is relatively 'smooth' and therefore slower to sediment on centrifugation than the other strains used, so that loss during washing tends to become appreciable. When steps were taken to decrease this loss to a minimum, the matings 58-161/F $+\times W-677 / \mathrm{F}-$ and $58-161 / \mathrm{F}-\times W-677 / \mathrm{F}+$ produced the same number of prototrophs on $M A+B_{1}$. When, however, samples of these same two mixtures were plated, under the same conditions, on $\mathbf{M A}$ alone and on $\mathbf{M A}+\mathbf{B}_{1}+\mathrm{T}$, the relative efficiency of the two matings varied widely, as Table 3 shows. These findings have been confirmed and offer

Table 3. The effect of growth factor supplements on the relative efficiency of 58-161/F $+\times W-677 / F-$ and 58-161 $/ F-\times W-677 / F+$ matings

Standard recombination technique employed

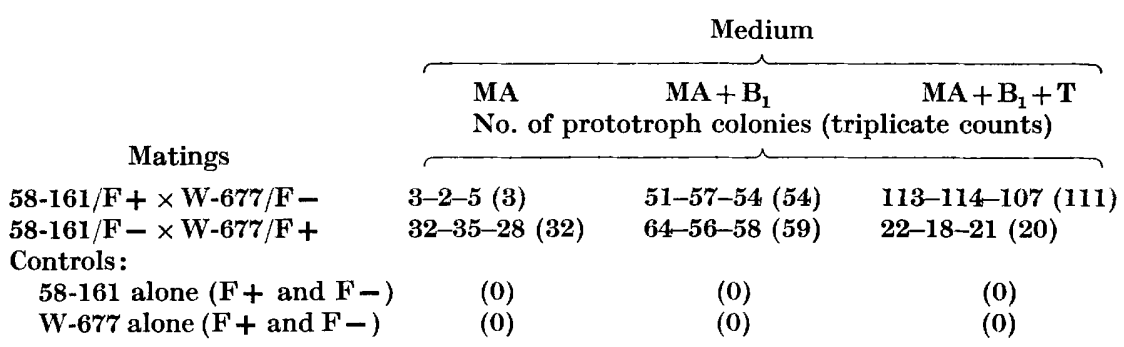

MA $=$ minimal agar $; B_{1}=$ thiamine $0.0005 \%(w / v) ; T=$ threonine $0.0025 \%(w / v) ;$ strain 58-161 $=M-T+L+B_{1}+$; strain $W \cdot 677=M+T-L-B_{1}-;()=$ average of triplicate counts.

some additional evidence for one-way transfer of genetic material from the $\mathbf{F}+$ to the $\mathbf{F}-$ strain. Thus when $\mathrm{W}-677$, requiring three growth factors ( $T, L, B_{1}$ ), is $F-$, the addition of each successive supplement to MA should reduce the number of genetic deficiencies to be made good by transfer from 58-161/F + in order to allow growth, and should therefore increase the apparent recombination rate. This in fact occurs. On the other hand, 58-161 is $\mathrm{M}$ - only, so that the efficiency of the $\mathrm{W}-677 / \mathrm{F}+\times 58-161 / \mathrm{F}-$ cross should be unaffected by $B_{1}$ and $T$ supplements, except insofar as these supplements might encourage syntrophic growth. Why the addition of threonine decreases the efficiency of this mating is not known, although it may possibly act as a methionine inhibitor. Teas, Horowitz \& Fling (1948), working with a doubly deficient Neurospora mutant, implicated homoserine as the precursor of both threonine and methionine in this strain and reported inhibition of growth in the presence of excess methionine which was reversed by increasing the threonine concentration. 
The relationship of the $F+$ agent to the phenotype of recombinants

Previous analysis of 404 prototroph colonies from sixteen separate $58-161 / F+\times W-677 / F-$ crosses had shown that, while 279 had a pattern of unselected marker characters (Lac, Mann, $T_{1}$ and $T_{3}$ ) different from that of either parent, 103 showed the phenotype of W-677 and only four that of 58-161. Moreover, the four prototrophs displaying the 58-161 phenotype all arose among thirty prototrophs from two consecutive matings. If these two aberrant matings are excluded, then of 374 prototrophs from fourteen separate matings, ninety-seven had the phenotype of W-677 and none that of 58-161. If the two fermentative reactions (Lac, Mann) alone are considered, $62 \%$ of prototrophs had the W-677 phenotype of unselected markers. Discovery of the $\mathbf{F}+$ factor suggested that this gross bias of recombinants towards the phenotype of the $\mathbf{F}$ - (or gene acceptor) strain might be reversed by transposing the $F$ potential of the mating partners. The effect of $F+$ transposition on the phenotype of recombinants is clearly demonstrated by the results of the two experiments presented in Table 4. The number of prototrophs tested is small but the results are clear-cut and reproducible, although

Table 4. The effect of $F+$ transposition on the phenotype of prototrophs from otherwise similar crosses

No. of protroph colonies having the phenotype of

Matings $\quad$ 58-161 W-677 combinations Total

Exp. 1. Marker characters = Lac, Mann, Mal, Gal, SM

\begin{tabular}{|c|c|c|c|c|}
\hline $58-161 / S^{r} / F+\times W-677 / F-$ & $\mathbf{0}$ & 11 & 4 & 15 \\
\hline $58-161 / \mathrm{S} r / F-\times W-677 / F+$ & 11 & $\mathbf{0}$ & $\mathbf{3}$ & 14 \\
\hline $58-161 / \mathrm{S} / \mathrm{F}+\times W-677 / \mathrm{F}+$ & 4 & 6 & 4 & 14 \\
\hline
\end{tabular}

Exp. 2. Marker characters $=$ Lac, Mann, phages $T_{1}, T_{3}$

$\begin{array}{lrrrr}58-161 / F+\times W-677 / F- & 0 & 8 & 2 & 10 \\ 58-161 / F+\times W-677 / F+ & 13 & 0 & 7 & 20 \\ 58-161 / F+\times W-677 / F+ & 8 & 7 & 5 & 20\end{array}$

Strain 58-161 = Lac + Mann $+\mathrm{Mal}+\mathrm{Gal}+$ phages $\mathbf{T}_{1}{ }^{8} \mathbf{T}_{3}{ }^{r}$

Strain W-677 = Lac - Mann - Mal - Gal - phages $\mathbf{T}_{1}{ }^{r} \mathbf{T}_{\mathbf{3}}{ }^{8}$

the proportion of prototrophs having new combinations of unselected markers to those having the F - phenotype seems to vary widely from one experiment to another irrespective of the marker pattern used for analysis. Since all these recombinants were obtained by prototroph selection, it was pertinent to determine whether recombinants selected by some other method showed bias of their nutritional requirements towards those of the $F-$ partner. Strain 58-161/F + was mated with W-677/Sr/F - on MA + Lac + SM, supplemented with all the growth factors required by both strains $\left(M, T, L, B_{1}\right)$. Since 58-161 is $\mathrm{Lac}+\mathrm{S}^{s}$ and $\mathrm{W}-677$ is $\mathrm{Lac}-\mathrm{Sr}$, only $\mathrm{Lac}+\mathrm{Sr}^{\mathrm{r}}$ recombinants can develop on this medium. Control experiments showed that no colonies arose from back-mutation when each strain was plated separately. Of forty- 
eight recombinant colonies selected in this way, all grew on MA + TLB 1 and only one on $\mathbf{M A}+\mathbf{M}$ (this isolate also grew on MA alone). Analysis of these strains was restricted by contamination of the available amino-acid preparations by thiamine. However, eleven of twenty-four of these recombinants were found to require $\mathrm{T}+\mathrm{L}$ for growth and since $c .90 \%$ of prototrophs from similar crosses on $\mathrm{MA}+\mathrm{B}_{1}$ are $\mathrm{B}_{1}$-dependent (Lederberg, 1947) it may be assumed that nearly all of these were $\mathrm{TLB}_{1}$ - and, therefore, of $\mathrm{W}-677 / \mathrm{F}-$ phenotype. The converse of this experiment after $\mathrm{F}+$ transposition has not yet proved possible due to difficulty in obtaining a stable Lac - mutant of $58-161 / \mathrm{Sr} / \mathrm{F}-$. It is clear that this dependence of phenotype on the $\mathbf{F}+$ relationships of a mating invalidates the evidence for at least a proportion of genetic linkages previously postulated for K-12. For instance, Newcombe \& Nyholm $(1950 a, b)$ tentatively suggested linkage between $\mathbf{S}^{\mathbf{r}}$ and the biotin and methionine loci as the result of reversed crosses in which $\mathbf{S}^{r}$ was introduced alternately into each parent as in matings $\mathbf{1}$ and $\mathbf{2}$ in Table 5 . Moreover, using 58-161 and W-677, they observed evidence of linkage between $S^{r}$ and fermentation of the sugars Gal, Mal, Xyl, Arab but not of Lac. Reference to Table 5 shows that when the same reverse crosses are carried out after $\mathrm{F}+$ transposition (matings 3 and 4) the apparent linkage of $\mathrm{S}^{\mathrm{r}}$ is the opposite of that implied by matings 1 and 2, indicating that $S^{r}$ is not linked with methionine. When the sugar

\section{Table 5. The effect of $F+$ transposition on the inheritance of streptomycin resistance in reversed crosses}

$\begin{array}{lrrr}\text { Matings } & \overbrace{\mathrm{S}^{r}}^{\text {No. of prototrophs }} & \mathrm{S}^{\mathrm{s}} & \text { No. examined } \\ \text { 1. } 58-161 / \mathrm{Sr} / \mathrm{F}+\times \mathrm{W}-677 / \mathrm{F}- & 3 & 149 & 152 \\ \text { 2. } 58-161 / \mathrm{F}+\times \mathrm{W}-677 / \mathrm{Sr} / \mathrm{F}- & 146 & 5 & 151 \\ \text { 3. } 58-161 / \mathrm{S} / \mathrm{F}-\times \mathrm{W}-677 / \mathrm{F}+ & 56 & 8 & 64 \\ \text { 4. } 58-161 / \mathrm{F}-\times \mathrm{W}-677 / \mathrm{Sr} / \mathrm{F}+ & 6 & 54 & 60\end{array}$

fermentations of prototrophs from these $S^{s} \times S^{r}$ crosses are examined the same contrary results are obtained, matings 1 and 2, for example, suggesting positive linkage and matings 3 and 4 negative linkage between $\mathrm{Sr}^{\mathrm{r}}$ and $\mathrm{Mal}+$. Thus the evidence of Tables 4 and 5 invalidates the evidence for the postulated linkages between loci for growth requirements and sugar fermentations, streptomycin and phage susceptibility, and between loci for streptomycin and sugar fermentations.

\section{DISCUSSION}

Since all the salient findings described above have been independently discovered and reported by Lederberg $e$ t al. (1952), and by Cavalli, Lederberg \& Lederberg (1953), there can be little doubt as to the validity of the results themselves. Their interpretation, however, is controversial. The chief point at issue, from which any ultimate concept of the physiological and genetic basis of recombination in Bact. coli must stem, is whether the phenomenon is fundamentally one of zygote formation followed by crossing-over and segregation 
in which the full chromosomal content of each partner participates more or less equally but in which the phenotypic expression of segregants may be profoundly modified by elimination of chromosomal segments introduced by the $\mathrm{F}+$ partner (Lederberg, 1949; Lederberg et al. 1952), or whether there is a one-way transfer of restricted groups of genes from the $\mathbf{F}+$ to the $\mathrm{F}-$ parent, possibly followed by crossing-over and meiosis limited to the immigrant genes and their alleles, so that the genotype of the progeny remains basically that of the $\mathrm{F}$ - parent (see Hayes, 1952 $a, b$ and the following discussion).

The concept of one-way gene transfer arose from the observation that SM destroyed the fertility of $\mathbf{F}-$ but not of $\mathbf{F}+$ cells. The essential validity of this observation was confirmed by Lederberg (personal correspondence) who found that while $S^{s} \mathbf{F}+\times S^{r} \mathbf{F}-$ crosses were productive on $S M-$ minimal agar, the fertility of $\mathbf{S} \mathbf{F}+\times \mathbf{S}^{\mathrm{s}} \mathbf{F}-$ crosses was negligible. Moreover $\mathbf{F}-$ cells which have been converted to $\mathbf{F}+$ behave as 'natural' $\mathbf{F}+$ cells in relation to SM, irrespective of their genotype. There is thus little doubt that SM exerts a differential effect on $\mathbf{F}+$ and $\mathbf{F}-$ cells. Since both types of cell are equally sensitive to the lethal action of the drug it is logical to conclude that $\mathbf{F}+$ cells must possess an agent, intimately associated with fertility and at least relatively resistant to the action of $\mathrm{SM}$, which is absent from $\mathbf{F}-$ cells.

The effect of ultraviolet light in stimulating the fertility of $F+$, but not of $\mathbf{F}$-, cells (Hayes, 1952 $b$ ) confirmed the possession by the former of an additional function related to the recombination process. The similarity of the conditions under which exposure of $\mathbf{F}+$ cells to ultraviolet became effective, to those required for maturation of prophage in lysogenic bacteria suggested that some agency of the nature of virus or prophage might be the instrument of gene transfer (Lwoff et al. 1950a, b; Lwoff, 1951). This ultraviolet work has now been in part repeated with each of two non-lysogenic, F + mutants of K-12 (kindly supplied by Dr A. Lwoff and Dr E. Wollman, and by Dr J. Lederberg) with the same results, so that the effect of ultraviolet on the recombination potential of $\mathbf{F}+$ cells is a primary one and not secondary to release of $\lambda$ phage. Recent work on the action of ultraviolet in inducing synthesis of new substances such as pyocines and colicines (as well as of phage) for which the cells have a covert propensity (Jacob, Siminovitch \& Wollman, 1951; Lwoff, 1953), enlarges the field of speculation as to the mechanism of fertility enhancement of $\mathbf{F}+$ strains of $\mathbf{K}-12$. It was thought not improbable that the agent of genetic transfer, while clearly not $\lambda$ phage (Lederberg et al. 1952), or other potentially lytic phage, might be a nonpathogenic virus whose only overt function was to act as a genetic carrier. The discovery of the $\mathrm{F}+$ factor with its high efficiency of transfer to $\mathrm{F}-$ cells, its replication within them and its essential role in recombination, appeared to offer strong vindication of this theory. The fact that the great majority of $\mathbf{F}-$ cells, infected with $\mathbf{F}+$ factor derived from cells of complementary genotype, showed no phenotypic alteration did not exclude $\mathbf{F}+$ as a genetic carrier, since effective association of such a carrier with genes from the cell it inhabits might well occur only under exceptional physiological conditions. This interpretation appeared the more plausible in view of the 
difficulty of accounting for the low rate of recombination among the cells of potentially fertile bacterial clones by more orthodox sexual mechanisms.

The factual relationship of the $\mathbf{F}+$ factor to recombination is not in dispute: $\mathbf{F}-\times \mathbf{F}-$ matings are completely sterile; maximum fertility is shown by $\mathbf{F}+\times \mathbf{F}-$ matings, while the fertility of $\mathbf{F}+\times \mathbf{F}+$ matings is much lower. Lederberg et al. (1952) tentatively suggest that this is compatible with a concept of relative sexuality, whereby the fertility of different crosses would be proportional to the $\mathbf{F}+$ differential between the partners. Thus there would exist different grades of $\mathbf{F}+, \mathbf{F}-$ having a grade of zero, so that the highest recombination rate would be given by $\mathbf{F} 4+\times \mathbf{F}-$ crosses and progressively lower rates by the series of crosses $\mathrm{F} 3+\times \mathrm{F}-, \mathrm{F} 2+\times \mathrm{F}-$ or $\mathrm{F} 4+\times \mathrm{F} 2+$, $\mathrm{F} 4+\times \mathrm{F} 3+$ and so on. In support of this they show that the ratio of efficiency of $\mathrm{F}+\times \mathrm{F}+: \mathrm{F}+\times \mathbf{F}-$ crosses may vary widely when various combinations of different auxotrophic mutants are tested. On the other hand, Table 3 of the present paper shows that the relative efficiency of 58-161/F $+\times$ $\mathrm{W}-677 / \mathrm{F}-$ and $58-161 / \mathrm{F}-\times \mathrm{W}-677 / \mathrm{F}+$ crosses can vary from $1: 10$ to $5: 1$ depending on the addition to, or withdrawal from, the minimal medium of growth factor supplements. It is simpler to suppose that fertility depends on the presence of a gene carrier in $\mathbf{F}+$ cells and its absence from $\mathbf{F}-$ cells. The greater productivity of $\mathbf{F}+\times \mathbf{F}-$ over $\mathbf{F}+\times \mathbf{F}+$ crosses is thus explained since in the former every contact between an $\mathbf{F}+$ and an $\mathrm{F}-$ cell is a potentially fertile mate. The occurrence of limited fertility in $\mathbf{F}+\times \mathbf{F}+$ crosses requires the assumption that a proportion of $\mathbf{F}+$ cells from each parental population becomes effectively $\mathbf{F}-$. It is evident that many $\mathbf{F}+$ cells must extrude or otherwise liberate their $\mathbf{F}+$ agent, in order to account for its transmissibility to $\mathbf{F}$ - cells, so that such cells might become effectively $\mathbf{F}-$ until reinfected by $\mathrm{F}+$ agent from either homologous or heterologous cells. In the latter case a small proportion of reinfected cells would become recombinants. Since in $\mathbf{F}+\times \mathbf{F}+$ crosses the majority of contacts would be between $\mathbf{F}+$ cells which form potentially infertile mates, a low degree of fertility would be expected. Direct evidence for the presence of $\mathbf{F}-$ cells in $\mathbf{F}+$ populations is lacking and would be difficult to obtain since their existence must be transitory due to the efficiency of the $\mathrm{F}+$ conversion process. All of 140 colonies tested from the plating of a 58-161/F + clone were $\mathrm{F}+$. There is, however, some significant indirect evidence. For instance, Table 4 demonstrates that in $\mathbf{F}+\times \mathbf{F}-$ matings the majority of prototrophs carry the phenotype of the $\mathbf{F}-$ parent and none that of the $\mathbf{F}+$ parent. In prototrophs from $\mathrm{F}+\times \mathrm{F}+$ crosses, however, the phenotypes of both parents are more or less equally represented, while the proportion of prototrophs showing new combinations of characters is the same as before. If a proportion of the cells of an $\mathbf{F}+$ clone are transiently $\mathbf{F}-$, then treatment of an F+ culture with SM should destroy the fertility of these F - cells. Provided that mating can occur only between $\mathbf{F}+$ and $\mathbf{F}-$ cells, it follows that if only one $\mathbf{F}+$ parent culture in an $\mathbf{F}+\times \mathbf{F}+$ cross is treated with $\mathbf{S M}$, then the treated parent should behave as pure $\mathbf{F}+$ and the untreated parent as pure $\mathbf{F}$ - as judged by analysis of the unselected marker patterns of the 
resulting prototrophs. This has recently been demonstrated experimentally, irrespective of which $\mathbf{F}+$ parent in the cross was subjected to SM treatment. When both F + parents were treated with SM, the cross was sterile. Again, if either $\mathbf{F}+$ parent in an $\mathbf{F}+\times \mathbf{F}+$ cross is treated with ultraviolet light the prototroph yield increases markedly while the phenotype of prototrophs shifts markedly towards that of the unirradiated strain, i.e. the irradiated parent behaves as if its ' $F+$ grade' had been increased. The theory of relative sexuality would therefore predict that if both $\mathrm{F}+$ parents were irradiated, the prototroph count should fall to its former level from restoration of the relative $\mathbf{F}+$ grades on both sides of the cross. In fact, when both $\mathbf{F}+$ parents are irradiated the prototroph count rises to a higher level than when either parent alone is treated with ultraviolet.

The parental phenotypes are not always equally distributed among prototrophs from various $\mathbf{F}+\times \mathbf{F}+$ crosses, but since in most of these experiments the same $\mathbf{F}+$ agent was harboured by both parents (as a result of previous direct or serial transmission from one to the other) the variable results would point to different degrees of stability of $\mathrm{F}+$ in different strains rather than to any qualitative grades of fertility involving all the cells of a strain.

Aberrant linkage behaviour in K-12 has been noted by several workers (Lederberg, 1949, 1950; Newcombe \& Nyholm, 1950a-c). The attention of Lederberg himself was drawn to these aberrations by the apparent elimination of certain chromosomal segments, involving especially the SM and Mal loci, from persistent K-12 diploids which consequently appeared hemizygous for these characters. It was then found that the segment subject to elimination was that contributed by the $\mathrm{F}+$ parent. Lederberg et al. (1952) therefore tentatively explained the bias of recombinants towards the F phenotype by the elimination of segments of the $\mathbf{F}+$ chromosome after zygote formation. Some of the experimental results recorded here would seem to require elimination of large parts of the $\mathrm{F}+$ chromosome, or of different parts of it under different environmental conditions of recombination, while the role of $\mathbf{F}+$ in the matter remains obscure. A more economical hypothesis is that only part of the $\mathbf{F}+$ chromosome is transmitted to the $\mathbf{F}-$ parent in the first place. If it is supposed, in addition, that the $\mathbf{F}+$ agent is the genetic carrier, then the determining role of this factor on fertility and phenotype falls neatly into place.

$\mathbf{F}+$ has many of the characters of a non-lytic infective agent. Since it is hardly to be supposed that its high efficiency of transfer is mediated by cytoplasmic fusion it must presumably leave the cell and, since it is not present in filtrates, remain adsorbed to the cell surface until taken up by an F - cell. These latter are two of the properties attributed to a hypothetical gene carrier as a result of previous work before the $\mathbf{F}+$ agent was discovered (Hayes, $1952 a, b)$. It was first shown by Cavalli (personal communication) and has been confirmed here and by Lederberg et al. (1952) that all recombinant prototrophs (with the single exception mentioned above) are $\mathbf{F}+$; there is also evidence that $\mathbf{F}+\times \mathbf{F}-$ combinations alone are fertile (so far as individual cells are concerned) and that the direction of gene transfer is from the 
$\mathbf{F}+$ to the $\mathbf{F}-$ parent. Under the actual conditions of recombination in an $\mathbf{F}+\times \mathbf{F}-$ cross on minimal agar, however, the efficiency of transfer of the $\mathrm{F}+$ agent is only $3-4 \%$. Assuming the premises are valid, there is thus a high degree of probability that the transfer of genes and of $\mathbf{F}+$ agent are correlated. Against this may be placed the results of a single experiment which seems to show fairly clearly (1) that while treatment of the $F+$ parent of a cross with ultraviolet light greatly increases the recombination rate, the efficiency of $\mathrm{F}+$ transmission is concurrently depressed and (2) that the action of $\mathrm{SM}$ on $\mathrm{S}^{\mathrm{s}} \mathrm{F}+$ reduces the $\mathrm{F}+$ conversion rate markedly in disproportion to the prototroph count when the treated suspension is mixed with an $\mathrm{S} \mathbf{F}$ - strain. Substantiation of the first of these findings would not invalidate the theory suggested here, for while the $\mathbf{F}+$ agent is favoured as the most likely carrier of the genetic elements, the two are regarded as distinct entities. If, for example, one of the effects of ultraviolet light was to increase 20-fold the proportion of $\mathbf{F}+$ agents effectively associated with parts of the bacterial chromosome, a concomitant $50 \%$ reduction in the efficiency of $\mathbf{F}+$ transfer (approximately that actually observed) would still allow a tenfold enhancement of recombination rate. While discussion of the differential action of SM on the transfer of genes and $\mathrm{F}+$ agent is, perhaps, premature, it is possible that an explanation may be found in different degrees of stability of complexes of SM with $\mathbf{F}+$ agent alone and with $\mathbf{F}+$ agent associated with chromosomal segments, such as have been described for coliphage $\mathbf{T}_{\mathbf{2}}$ and $\mathbf{T}_{\mathbf{4}}$, with and without an external coating of deoxyribonucleic acid, by Cohen $(1947 a, b)$.

The main aim of this discussion has been to present a theory of recombination which is sufficiently plausible to serve as a useful working hypothesis. It is possible that its substantiation in principle might reveal recombination in Bact. coli as a key stage in the evolution of mature sexual processes from simple genetic transformations. The speculative nature of the theory is fully admitted, however, and it is clear that a generally acceptable concept of the intimate mechanism of recombination must await the results of further experimental work.

I wish to express my indebtedness to Dr L. L. Cavalli and Dr J. Lederberg, not only for gifts of cultures but especially for the stimulus which the free exchange of views and experimental results with them has offered me; and to Dr D. A. Mitchison for the benefit of many discussions with him on this subject.

\section{REFERENCES}

Cavalli, L. L., Lederberg, J. \& Lederberg, E. M. (1953). An infective factor controlling sex compatibility in Bacterium coli. J. gen. Microbiol. 8, 89.

Cavalli, L. L. \& Maccacaro, G. A. (1950). Chloromycetin resistance in E. coli, a case of quantitative inheritance in bacteria. Nature, Lond. 166, 991.

CoHen, S. S. $(1947 a)$. Streptomycin and desoxyribonuclease in the study of variations in the properties of a bacterial virus. J. biol. Chem. 168, 511 .

Conen, S. S. $(\mathbf{1 9 4 7 b})$. The synthesis of bacterial viruses in infected cells. Cold Spr. Harb. Symp. quant. Biol. 12, 35. 
Davis, B. D. (1950). Nonfiltrability of the agents of genetic recombination in Escherichia coli. J. Bact. 60, 507.

HAYES, W. (1952a). Recombination in Bact. coli K-12: uni-directional transfer of genetic material. Nature, Lond. 169, 118.

HAYES, W. (1952b). Genetic recombination in Bact. coli K-12: analysis of the stimulating effect of ultra-violet light. Nature, Lond. 169, 1017.

$\mathbf{J}_{\mathrm{ACOB}}$, F., Siminovitch, L. \& Wollman, E. (1951). Induction de la production d'une colicine par la rayonnement ultraviolet. C.R. Acad. Sci., Paris, 233, 1500.

LEDERBERG, J. (1947). Gene recombination and linked segregations in Escherichia coli. Genetics, 32, 505.

Lederberg, J. (1949). Aberrant heterozygotes in Escherichia coli. Proc. Nat. Acad. Sci., Wash. 35, 178.

Lederberg, J. (1950). Segregation in Escherichia coli. Genetics, 35, 119 (Abstract).

Lederberg, J. (1951). Prevalence of Escherichia coli strains exhibiting genetic recombination. Science, 114, 68.

Lederberg, J., Cavalli, L. L. \& Lederberg, E. M. (1952). Sex compatibility in Escherichia coli. Genetics, 37, 720.

Lederberg, J. \& TAtum, E. L. (1946). Gene recombination in Escherichia coli. Nature, Lond. 158, 558.

Lworf, A. (1951). Conditions de l'efficacité inductrice du rayonnement ultraviolet chez une bactérie lysogène. Ann. Inst. Pasteur, 81, 370.

Lworf, A. (1953). The nature of phage reproduction. Contribution to Symposium on The Nature of Virus Multiplication. Soc. gen. Microbiol. Symp. Cambridge University Press. (In the Press.)

Lwoff, A., Siminovitch, L. \& KJelgaard, N. (1950a). Induction de la lyse bacteriophagique de la totalité d'une population microbienne lysogène. C.R. Acad. Sci., Paris, 231, 190.

Lwoff, A., Siminovitch, L. \& KJelgaard, N. (1950b). Induction de la production de bacteriophages chez une bacterié lysogène. Ann. Inst. Pasteur, 79, 815.

Newcombe, H. B. \& Hawirko, R. (1949). Spontaneous mutation to streptomycin resistance and dependence in Escherichia coli. J. Bact. 57, 565.

Newcomвe, H. B. \& Nyнolm, M. H. (1950a). Crosses with streptomycin resistant and dependent mutants of Escherichia coli. Genetics, 35, 126 (Abstract).

Newcomвe, H. B. \& Nyнolm, M. H. (1950b). The inheritance of streptomycin resistance and dependence in crosses of Escherichia coli. Genetics, 35, 603.

Newcombe, H. B. \& Nyноцм, M. H. (1950c). Anomalous segregation in crosses of Escherichia coli. Amer. Nat. 84, $45 \%$.

Tatum, E. L. \& Lederberg, J. (1947). Gene recombination in the bacterium Escherichia coli. J. Bact. 53, 673.

Teas, H. J., Horowitz, N. H. \& Fling, M. (1948). Homoserine as a precursor of threonine and methionine in Neurospora. J. biol. Chem. 172, 651.

Weigle, J. J. \& Delbrück, M. (1951). Mutual exclusion between an infecting phage and a carried phage. J. Bact. 62, 301.

Zelue, M. R. \& Lenerberg, J. (1951). Single cell isolations of diploid heterozygous Escherichia coli. J. Bact. 61, 351. 